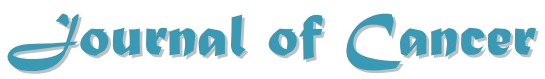

$2011 ; 2: 76-80$

Research Paper

(C) Ivyspring International Publisher. All rights reserved

\title{
Patients with Localised Prostate Cancer (T1 - T2) Show Improved Overall Long-Term Survival Compared to the Normal Population
}

\section{Michael J. Mathers ${ }^{1 凶}$, Stephan Roth², Monika Klinkhammer-Schalke3, Michael Gerken ${ }^{3}$, Ferdinand Hofs- taedter ${ }^{3}$, Stefan Wilm ${ }^{4}$, Theodor Klotz ${ }^{5}$}

1. Urologische Gemeinschaftspraxis Remscheid in cooperation with Helios Clinic Wuppertal, Universitiy Witten/Herdecke, Germany

2. Department of Urology, Helios Clinik Wuppertal, University Witten/Herdecke, Germany

3. Tumor Center Regensburg, Germany

4. Institute of General Practice and Family Medicine, University Witten/Herdecke, Germany

5. Department of Urology, Weiden, Germany

Corresponding author: Michael J. Mathers, M.D. Ph.D., Urologische Gemeinschaftspraxis Remscheid, Fastenrathstr. 1, 42853 Remscheid. Tel.: 0049-2919-291909; Fax: 0049-2191-291907; Email: irtima@t-online.de

Received: 2011.01.07; Accepted: 2011.02.07; Published: 2011.02.08

\begin{abstract}
Background: Little information is available on the long-term outcomes of patients with localised prostate cancer.

Objective: To examine the long-term survival of patients with localised prostate gland carcinoma TI - T2, N0, M0 (UICC stage I and II) compared to the normal population.

Design: Retrospective cohort.

Setting: Regensburg, Germany.

Participants: Data on 2/2I patients with histologically-confirmed, localised prostate cancer diagnosed between 1998 and 2007 were extracted from the cancer registry of the tumour centre in Regensburg, Germany.

Measurements: Overall survival rate in the patient cohort was estimated and compared to the expected survival rate of a comparable group in the general population derived from the official life-tables of Germany stratified by age, sex and calendar year.

Results: Ten years after diagnosis, patients with stage I and II localised prostate gland carcinoma had an approximately $10 \%$ increase in survival compared to the normal male population (Relative Survival = I I0.7\%, 95\%-Cl I06.6 - I I4.8\%).

Limitations: We did not examine the effect of cancer treatment or cancer aggressiveness on the overall survival of patients. We did not assess the incidence of subsequent non-primary cancers in our patient population or how this incidence affects the patients' follow-up care and survival.

Conclusions: Patients with stage I+II localised prostate gland carcinoma have improved survival compared with the normal male population. This finding cannot be explained solely by the administration of prostate carcinoma treatments, suggesting that men who participate in PSA screening may have better overall health behaviors and care than men who do not participate in screening. Future research should examine how treatment choice, especially an "active surveillance" approach to care, affects survival in these patients more than ten years after diagnosis.
\end{abstract}

Key words: prostate cancer; outcomes research; health status; social gradient of prevention; PSA

\section{Introduction}

The incidence of prostate cancer has increased in industrialized nations worldwide in the past three decades (1). Today, almost $20 \%$ of men over 50 years old will receive a prostate cancer diagnosis, and be- 
tween 1979 and 2006 the detection of prostate cancer increased among men less than 65 years of age by approximately 4.1-fold (1). These increases can be explained in-part by the implementation of extensive prostate-specific antigen (PSA) screening programs and the aging populations of industrialized nations $(2,3)$.

Although PSA testing increases prostate cancer incidence by improving the ability to detect prostate cancer cases in a population, it also allows for the recognition and treatment of prostate cancer in an early stage, thereby reducing the rate of death from prostate cancer $(2,4)$. Due to this shift in the stage at which men receive a prostate cancer diagnosis, wide-scale use of traditional curative treatments for prostate cancer (such as radical prostatectomy), which come with medical and quality of life side-effects, may not be justified. Indeed, the new guidelines of the Germany Society for Urology (DGU) (5) include "active surveillance" as an acceptable therapy option for low-risk prostate cancer, but research is needed on the long-term survival of these patients and the effect of treatment choice on survival before standardized treatment recommendations for localised, low-risk prostate cancer are possible.

There have been limited data available on men with localised prostate gland carcinoma in Europe with which to conduct necessary research on the long-term survival of patents with low-risk prostate cancer (6). The creation of regional cancer registries in the past 10-15 years, including that of the Federal Republic of Germany (FRG), has provided for the opportunity to close this research gap. In order to investigate the long-term outcomes of patients with localised prostate carcinoma in Germany, we used data from the regional tumour registry in Regensburg, Germany to evaluate the relative survival of patients with localised prostate gland carcinoma, as compared to the standardised age-adjusted survival of the normal Bavarian population.

\section{Methods}

We extracted epidemiological and clinical data from the Regensburg regional tumour registry on patients diagnosed between 1998 and 2007 with prostate cancer. The cancer tumour registry of Regensburg is a population-based registry that records the diagnosis, treatment, and follow-up care of any known malignancy in cancer patients living in the districts of Oberpfalz and Niederbayern, Bavaria, Germany. The data for the registry are provided by primary care physicians, hospital staff and pathologists from the districts using standardised cancer registry forms. The registry captures more than $90 \%$ of all persons diagnosed with cancer located in the two districts, which have a combined population of approximately 2 million residents (6).

All patients included in this study had a histologically-confirmed prostate carcinoma (diagnosis C61), based on the International Classification of Diseases ICD-10 (8). The registry record for each patient included the initial clinical and the pathological stage according to the classification of the International Union Against Cancer (UICC) (9). We used this classification to select patients with early and locally-limited cancer UICC stages I and/or II, comprising patients with small tumour size (T1 and T2), negative nodal status (N0) and no distant metastasis (M0). Although not part of our primary study objective, we also selected patients with stage III and stage IV prostate cancer to evaluate the relative, long-term survival in patients with later stage prostate carcinoma. We ascertained the life-status of the registry patients using death-certificates and information from the registration offices of the patients' respective resident districts.

We calculated overall survival rates and relative survival rates of the cancer patients at 5 and 10 years post-diagnosis. The cumulative relative survival rate is defined as the ratio of the observed overall survival rate in the patient group and the expected survival rate of a comparable group from the general population matched with respect to age at diagnosis, sex and calendar year of diagnosis. For this comparison the official German life-tables from 1998 to 2007 were used, stratified according to age, sex and calendar year. We applied the software SURVSOFT for calculating overall survival choosing the standard life table (actuarial) method with one-year time intervals and for calculating relative survival choosing the method of Hakulinen in order to estimate expected survival (10). All patients - regardless of length of follow-up were included. We did not differentiate or control for the types of cancer treatments received by the patients, because we were interested in overall survival independent of treatment choice. Descriptive data analyses were performed using the statistical software SPSS V.18.

\section{Results}

Table 1 shows the numbers, average ages and length of follow-up of the patients included in our analyses. Approximately $51 \%$ of all diagnosed tumours in the registry data were stage I+II localised tumours. The average age at diagnosis was 67.2 years (median: 67.6), the average length of follow-up was 6.4 years (median: 6.1). Table 2 and Figure 1 show the results of our overall survival calculations and relative 
survival analyses. Patients with stage I+II prostate cancer had an approximately 5\% increase in 5-year survival compared to the normal population (Relative survival $=104.7 \%, 95 \%-C I 103.2-106.2 \%)$ and an approximately $10 \%$ increase in 10-year survival compared with the normal population (Relative Survival $=110.7 \%, 95 \%-C I 106.6-114.8 \%$; Table 2, Figure 1).

Patients with stage III prostate cancer did not have significantly different 5-year or 10-year survival rates than the normal population (Relative Survival $=$ 101.9\%, 95\%-CI 99.7 - 104.2\% and 102.0\%, 95\%-CI 96.4 - 107.5\%, respectively; Table 2, Figure 1), while patients with stage IV prostate cancer had significant and clear 5-year and 10-year survival disadvantages compared to the normal population (Relative Survival $=54.4 \%, 95 \%-\mathrm{CI} 50.7-58.0 \%$ and $43.4 \%$, 95\%-CI $38.1-$ $48.7 \%$, respectively; Table 2, Figure 1).

Table I. Number, average age and follow-up of patients.

\begin{tabular}{lllll|l|l|}
\hline & \multicolumn{2}{l}{ Sample } & Age & \multicolumn{3}{l}{$\begin{array}{l}\text { Follow-up } \\
\text { (years) }\end{array}$} \\
$\begin{array}{l}\text { Prostate Cancer } \\
\text { Stage (UICC) }\end{array}$ & $\mathrm{N}$ & $\%$ & Mean & Median Mean & Median \\
I+II & 2121 & $50.6 \%$ & 67.2 & 67.6 & 6.4 & 6.1 \\
III & 954 & $22.8 \%$ & 65.5 & 65.7 & 6.5 & 6.5 \\
\hline IV & 1113 & $26.6 \%$ & 68.8 & 68.7 & 4.2 & 3.4 \\
\hline Total & 4188 & $100.0 \%$ & 67.2 & 67.3 & 5.8 & 5.7 \\
\hline
\end{tabular}

$\mathrm{UICC}=$ International Union Against Cancer

Table 2. Overall survival of patients, expected survival of comparable normal population, and relative survival of the patient cohorts at 5 - and 10 -years post-diagnosis by cancer stage.

\begin{tabular}{|c|c|c|c|c|c|c|}
\hline \multirow[t]{2}{*}{$\begin{array}{l}\text { Prostate Cancer Stage } \\
\text { (UICC) }\end{array}$} & \multicolumn{2}{|c|}{ Overall Survival of Patient Cohort (\%) } & \multicolumn{2}{|c|}{$\begin{array}{l}\text { Expected Survival of Comparable } \\
\text { Normal Population (\%) }\end{array}$} & \multicolumn{2}{|c|}{$\begin{array}{l}\text { Relative Survival of Patient Cohort (\%) } \\
(95 \% \text {-Confidence interval) }\end{array}$} \\
\hline & $5 Y$ & $10 \mathrm{Y}$ & $5 Y$ & $10 \mathrm{Y}$ & $5 Y$ & $10 \mathrm{Y}$ \\
\hline $\mathrm{I}+\mathrm{II}$ & 90.2 & 76.5 & 86.2 & 69.1 & $\begin{array}{l}104.7 \\
(103.2-106.2)\end{array}$ & $\begin{array}{l}110.7 \\
(106.6-114.8)\end{array}$ \\
\hline III & 89.9 & 75.0 & 88.2 & 73.6 & $\begin{array}{l}101.9 \\
(99.7-104.2)\end{array}$ & $\begin{array}{l}102.0 \\
(96.4-107.5)\end{array}$ \\
\hline IV & 44.9 & 28.2 & 82.6 & 64.9 & $\begin{array}{l}54.4 \\
(50.7-58.0)\end{array}$ & $\begin{array}{l}43.4 \\
(38.1-48.7)\end{array}$ \\
\hline Total & 78.2 & 63.0 & 85.7 & 69.0 & $\begin{array}{l}91.2 \\
(89.7-92.7)\end{array}$ & $\begin{array}{l}91.4 \\
(88.4-94.4)\end{array}$ \\
\hline
\end{tabular}

UICC = International Union Against Cancer; $Y=$ Number of years post-diagnosis

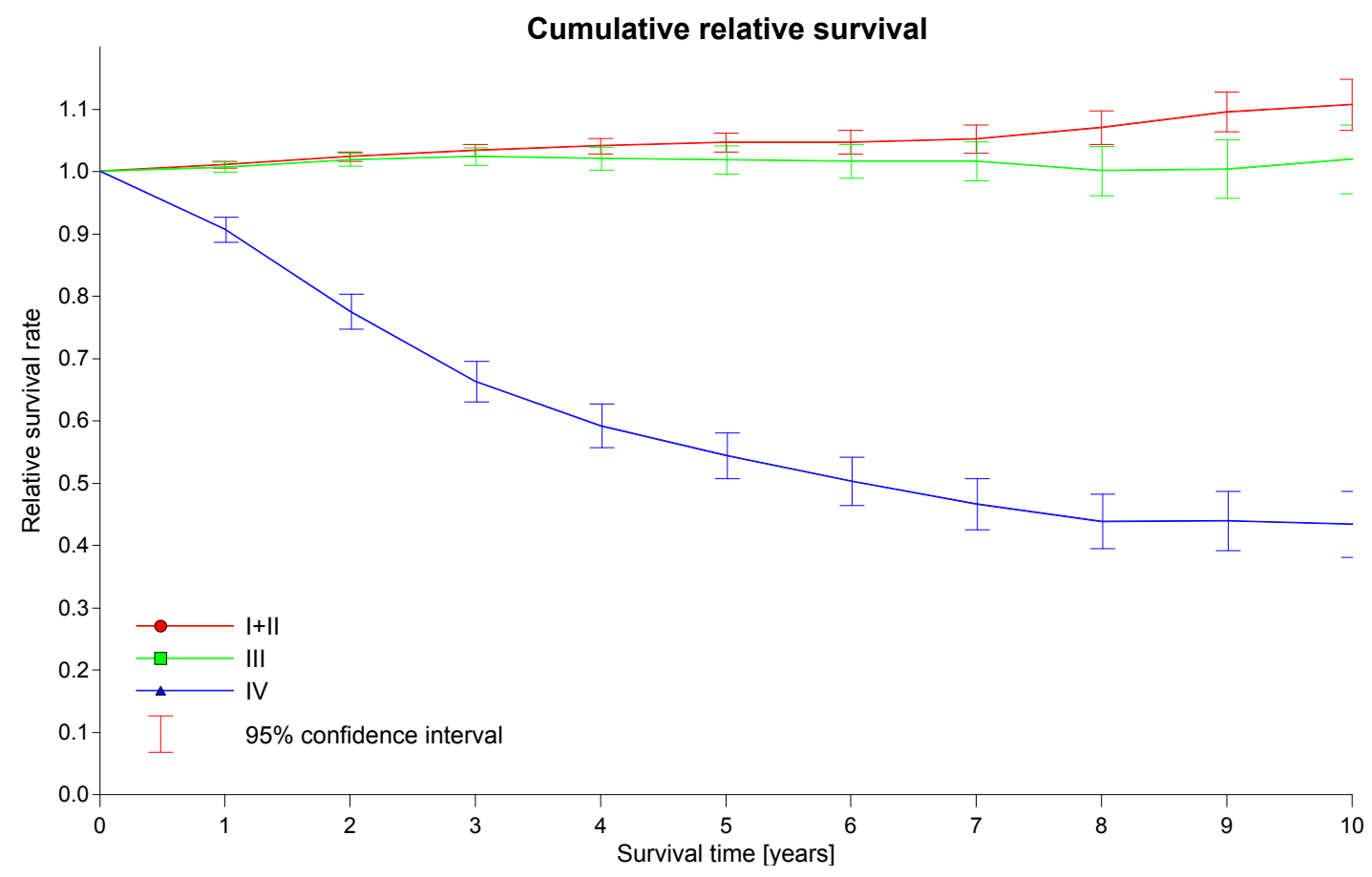

Figure I. Relative survival rates for the prostate cancer stage I+II, III and IV patient cohort. 


\section{Discussion}

Our analyses showed that patients with stage I+II localised prostate gland carcinoma have improved survival compared to the normal male population, and this relative survival advantage appears only 2-3 years after diagnosis (Figure 1). This finding cannot be explained definitively by the administration of prostate gland carcinoma treatments (e.g., radical prostatectomy, radiotherapy), which have been shown to result in a survival advantage only after several years $(11,12,13)$.

We suggest three primary explanations for our findings. First, as described in previous research, relatively healthy men take advantage of PSA-supported preventive measures and show reduced morbidity and improved survival compared to men who do not participate in PSA testing (14). Additionally, we know from the 2008 work of Fröhner et al. that in men 63 to 69 years of age increased comorbidity is a strong predictor of 10-year mortality in men receiving radical prostatectomy (15). Our results support these findings by suggesting that the health of men who undergo PSA-testing, especially those in the 50-70 year-old age range, is better overall (i.e., lower comorbidity) than that of men who do not participate in PSA screening. Second, research has shown that a cancer diagnosis can be a "teachable moment" that encourages patients to adopt better health behaviors $(16,17)$. The men in our sample who were diagnosed with stage I or II prostate cancer may have made more positive health choices compared to the general population in the first few years after their diagnosis. Third, the observed improved survival may result not only from the superior health-consciousness and behaviors of cancer patients, but also from socioeconomic advantages (e.g., higher levels of education and income) that make one more like to receive secondary prevention outreach by health care providers and the media $(18,19,20)$. The socioeconomic disparities in secondary prevention outreach and up-take are cited as a major weakness of PSA screening systems. Furthermore it is well possible that physicians exercise a more careful patient selection for prostate cancer screening.

The goal of treatment for prostate gland carcinoma should be the effective delivery of care to every diagnosed patient, and this care must take into account each patient's individual needs, living conditions, and tumour biology. Our finding that men with stage I+II prostate cancer have survival advantages independent of treatment choice suggests that the current standards of care in Germany - which result in almost $70 \%$ of prostate cancer patients under the age of 70 receiving radical prostatectomy-should change to include less invasive methods of treatment for cancers at low risk of progression (21). Accordingly, several European treatment guidelines now include "active surveillance" as an evidence-based method of treatment for localised, low-risk prostate carcinoma (5).

Limitations to our study include the fact that we did not examine the effect of individual, evidence-based treatments for localised prostate gland carcinoma or cancer aggressiveness (e.g., Gleason score) (21) on the overall survival of patients. We also did not evaluate whether all patients with stage I+II prostate cancer included in the study had underwent PSA screening to confirm our conclusion that the patients' survival advantage related to their participation in PSA testing. Lastly, we did not assess the incidence of subsequent non-primary cancers in our patient population or how this incidence affects the patients' follow-up care and survival (21). We plan to conduct future analyses to examine these questions in the German population.

\section{Conclusion}

Patients with localised, stage I+II prostate gland carcinoma demonstrated improved long-term health compared to the normal population, regardless of the treatment received during the first ten years after diagnosis. The finding suggests that that men who participate in PSA screening may have better overall health behaviors and care than men who do not participate in screening and that men who receive a cancer diagnosis may make positive health behavior changes after their diagnosis that improve their long-term survival. Future research should examine how treatment choice, especially an "active surveillance" approach to care, affects survival in these patients more than ten years after diagnosis. Research should also evaluate the long-term survival impact of socioeconomic disparities in the receipt of prostate cancer secondary prevention outreach and services.

\section{Conflict of Interest}

The authors have declared that no conflict of interest exists.

\section{References}

1. [Internet] Horner MJ, Ries LAG, Krapcho M, Neyman N, Aminou R, Howlader N, Altekruse SF, Feuer EJ, Huang L, Mariotto A, Miller BA, Lewis DR, Eisner MP, Stinchcomb DG, Edwards BK. SEER Cancer Statistics Review, 1975-2006, National Cancer Institute, Bethesda, MD. http://seer.cancer.gov/csr/1975_2006/ 
2. Schröder FH, Hugosson J, Roobol MJ, et al. Screening and Prostate-Cancer Mortality in a Randomized European Study. N Engl J Med. 2009;360:1320-1328.

3. Borre M, Nerstrøm B, and Overgaard J: The natural history of prostate carcinoma based on a Danish cancer population treated with no intent to cure. Cancer. 1997;80:917-928.

4. Catalona WJ, Smith DS, Ratliff TL, et al. Measurement of prostate-specific antigen in serum as a screening test for prostate cancer. N Engl J Med. 1991;324:1156-61.

5. DGU. S3-Leitlinie Prostatakarzinom, Version 1,0. DGU. 2009.

6. Hamilton AS, Albertsen PC, Johnson TK et al. 20-year outcomes following conservative management of clinically localized prostate cancer. JAMA. 2005;293(17):2095-101.

7. Klotz T, Hofstadter F, Gerken M. Interdisciplinary oncologic after-care exemplified by second primary tumours after bladder carcinoma. Urologe A. 2003;42:1485-1490.

8. World Health Organization. International Statistical Classification of Disease and Related Health Problems, Tenth Revision (ICD-10). World Health Organization. 1992.

9. Sobin LH, Wittekind CL. TNM classification of malignant tumours, 6th edition. New York: John Wiley \& Sons, 2002.

10. Geiss K, Meyer M, Radespiel-Tröger M, Gefeller $\mathrm{O}$. SURVSOFT-Software for nonparametric survival analysis. Computer Methods and Programs in Biomedicine. 2009;96(1): 63-71.

11. Fröhner M, Koch R, Litz RJ, Hakenberg O, Oehlschlaeger S, Wirth M: Interaction Between Age and Comorbidity as Predictors of Mortality After Radical Prostatectomy. J Urol. 2008;179:1823-1829.

12. Fröhner M, Koch R, Litz RJ, et al.: Detailed Analysis of Charlson Comorbidity Score as Predictor of Mortality After Radical Prostatectomy. Urology. 2008;72:1252-1257.

13. Ketchandji M, Kuo JF, Shahinian VB, Goodwin JS: Cause of death in older men after the diagnosis of prostate cancer. J Am Geriatr Soc. 2009;57:24-30.

14. Zeliadt SB, Etzioni R, Ramsey SD, Penson DF, Potosky AL. Trends in treatment costs for localised prostate cancer: the healthy screenee effect. Med Care. 2007 Feb;45(2):154-9.

15. Fröhner M, Koch R, Litz RJ, Hakenberg O, Oehlschlaeger S, Wirth M: Interaction Between Age and Comorbidity as Predictors of Mortality After Radical Prostatectomy. J Urol. 2008;179:1823-1829.

16. McBride CM, Scholes D, Grothaus LC, Curry SJ, Ludman E, Albright J. Evaluation of a minimal self-help smoking cessation intervention following cervical cancer screening. Prev Med. 1999 Aug;29(2):133-8.

17. Humpel N, Magee C, Jones SC. The impact of a cancer diagnosis on the health behaviors of cancer survivors and their family and friends. Support Care Cancer. 2007 Jun;15(6):621-30.

18. Hurrelmann K, Klotz T, Haisch J: Lehrbuch Prävention und Gesundheitsförderung. Bern: Huber 2004.

19. Lampert T: Tabakkonsum, sportliche Inaktivität und Adipositas. Dtsch Arztebl Int. 2010;107(1-2):1-7.

20. Raffle A, Muir Gray JA: Screening - Durchführung und Nutzen von Vorsorgeuntersuchungen. Bern, Göttingen, Toronto, Seattle: Huber 2009.

21. Weißbach L., Altwein J. Aktive Überwachung oder aktive Therapie beim lokalen Prostatakarzinom? Dtsch Ärztebl. 2009;106:371-376.

22. Gleason DF. The Veteran's Administration Cooperative Urologic Research Group: histologic grading and clinical staging of prostatic carcinoma. In: Tannenbaum M, ed. Urologic Pathology: The Prostate. Philadelphia: Lea and Febiger. 1977;171-198.

23. Mathers MJ, Zumbe J, Wyler S, Roth S, Gerken M, Hofstädter F, Klotz T. Is there evidence for a multidisciplinary follow-up after urological cancer? An evaluation of subsequent cancers. World J Urol. 2008 Jun;26(3):251-6. 